\title{
Repair on the Class 1070 No.1080 British-made 4-4-2 Tank Engine preserved in the Umekoji Steam Locomotive Museum
}

\author{
Naoki Bando* and Yasuyuki Fukuhara** \\ * Umekoji Steam Locomotive Museum, Kankiji-cho, Shimogyo-ku, Kyoto, Japan \\ E-mail:aed77290@star.odn.ne.jp \\ **West Japan Railway Company, 2-4-24 Shibata, Kita-ku, Osaka, Japan
}

\begin{abstract}
In this presentation, repair on the Class 1070 No.1080 British-made 4-4-2 tank engine preserved in the Umekoji Steam Locomotive Museum at Kyoto will be introduced.
\end{abstract}

Key words: Railway, Steam locomotive, Museum, Repair, Industrial heritage

Preservation of Steam locomotive in the Umekoji Steam Locomotive Museum

In September 2009, West Japan Railway Company (JR West) preserved a British-made 4-4-2 tank engine Class 1070 No.1080 in the Umekoji Steam Locomotive Museum at Kyoto. In this presentation, outline of repair process of this tank engine will be introduced through twenty-three next pictures.

1. No.1080, which is near at hand transferred from Nittetsu Mining Company, Tochigi Prefecture.

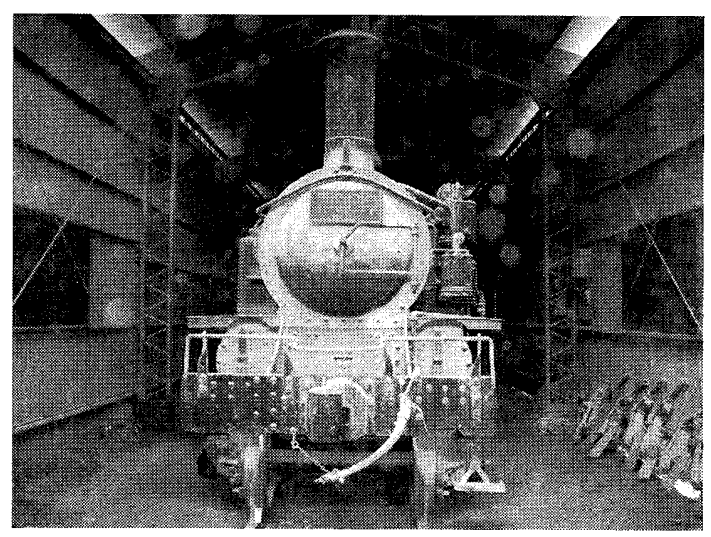


6. Fence construction for painting and restoration work.

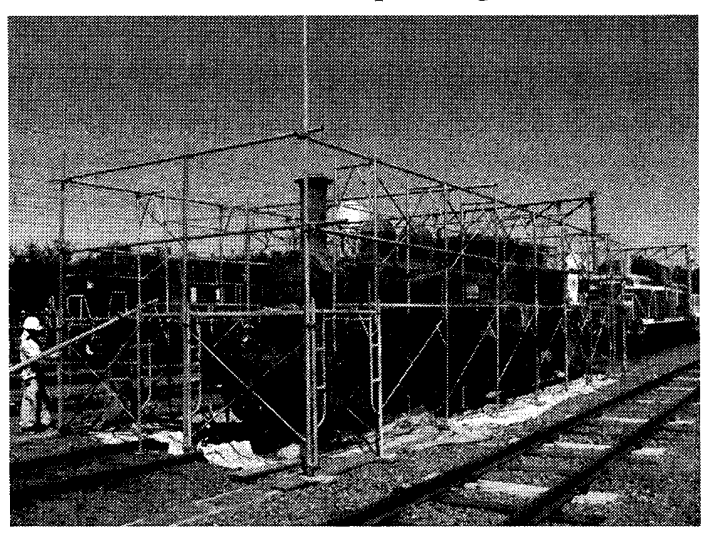

7. Front view of tank engine (It finished prevention rust painting work).

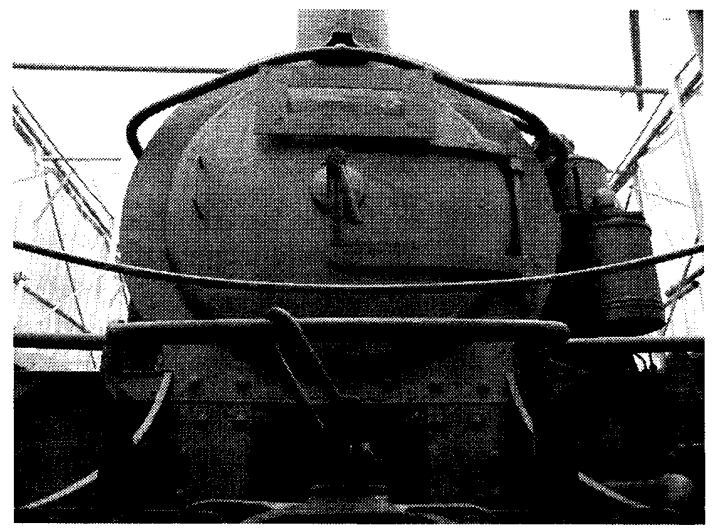

8. Leading truck (It finished prevention rust painting work).

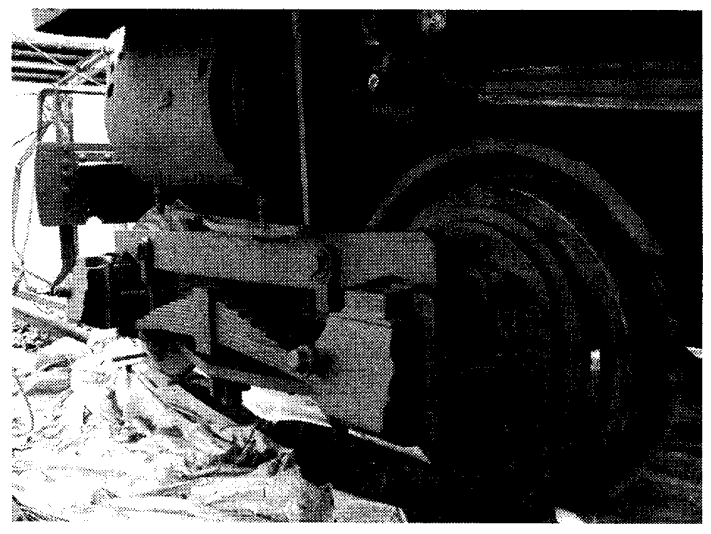

9. Safety valve (It finished prevention rust painting work).

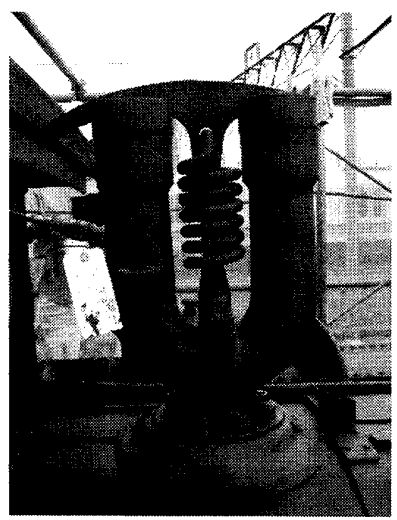


13. Polished water gauge cover.

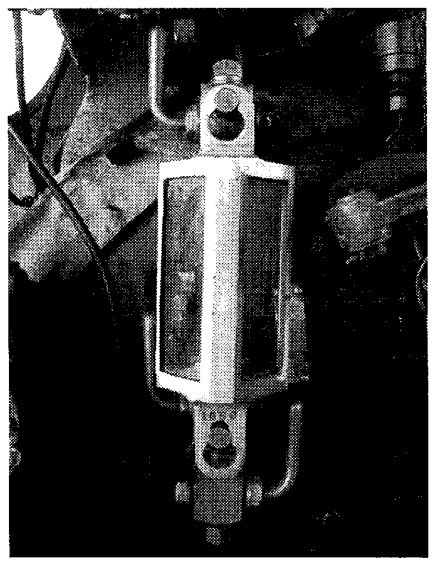

14. Repaired pressure gauge.

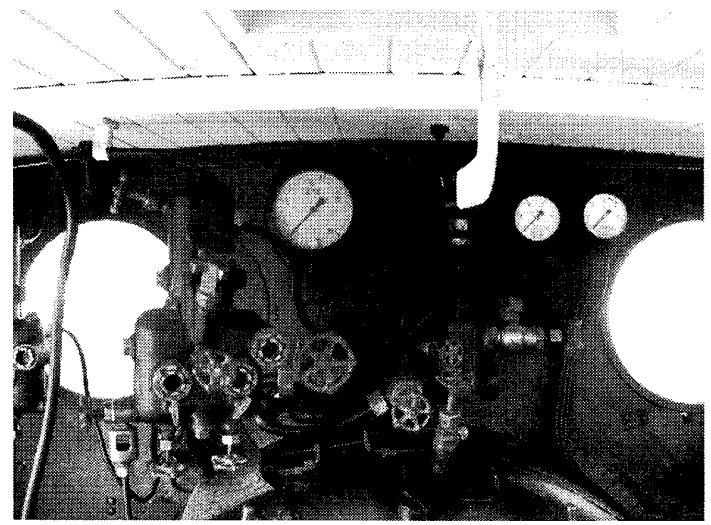

15. Coated steam distributing valve.

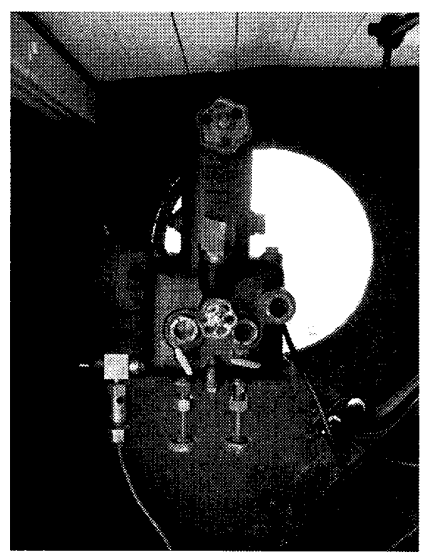


16. Coated Stephenson type valve gear.

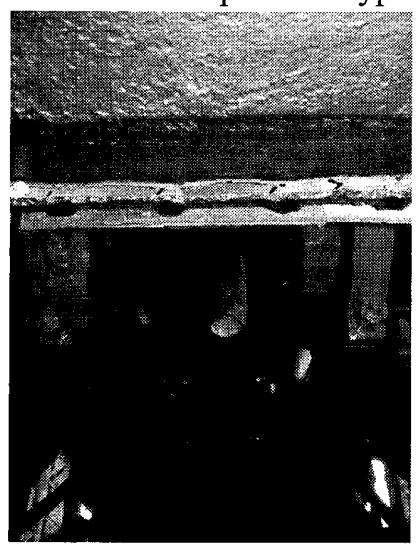

17. Surface of number-plate is now polishing.

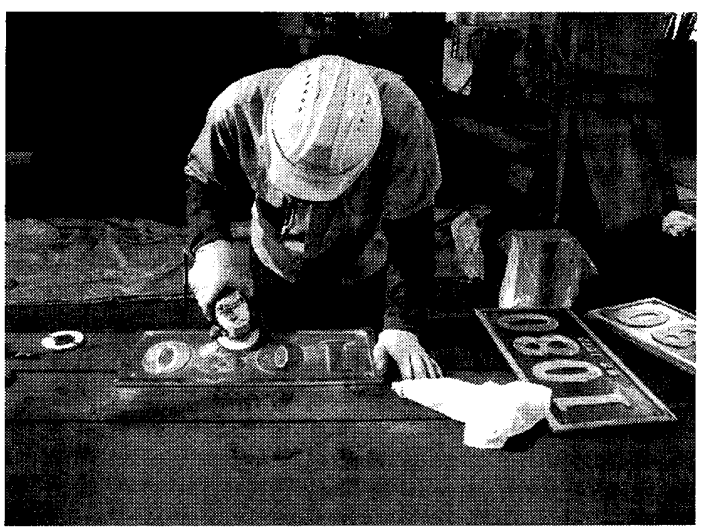

18. Beautifully burnished number-plate.

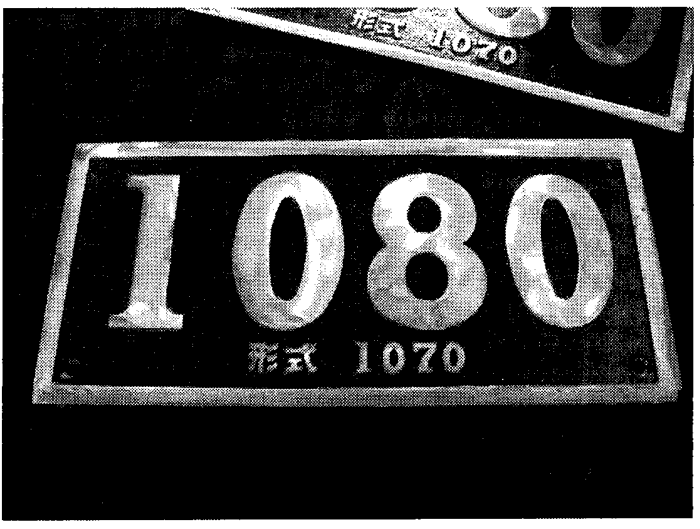

19. Under burnishing of main rod.

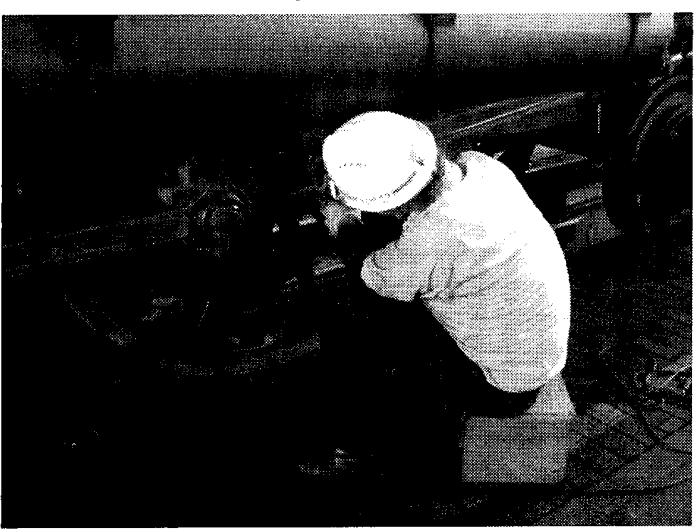


20. Under burnishing of driving wheels.

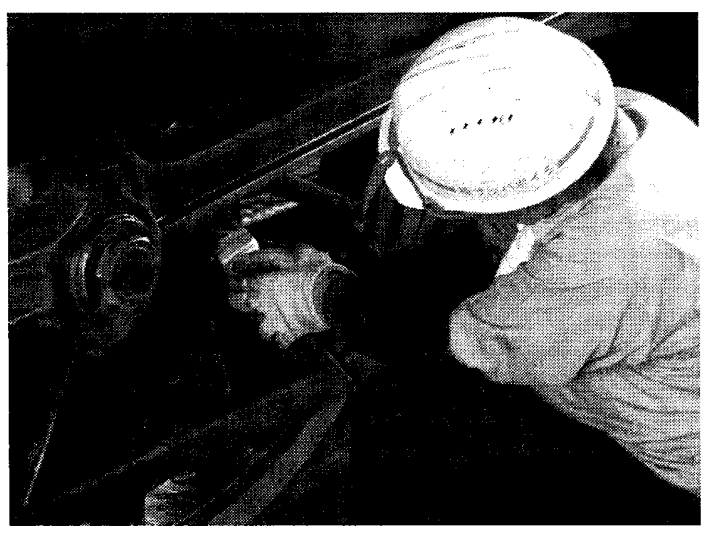

21. Official view of the No.1080 tank engine.

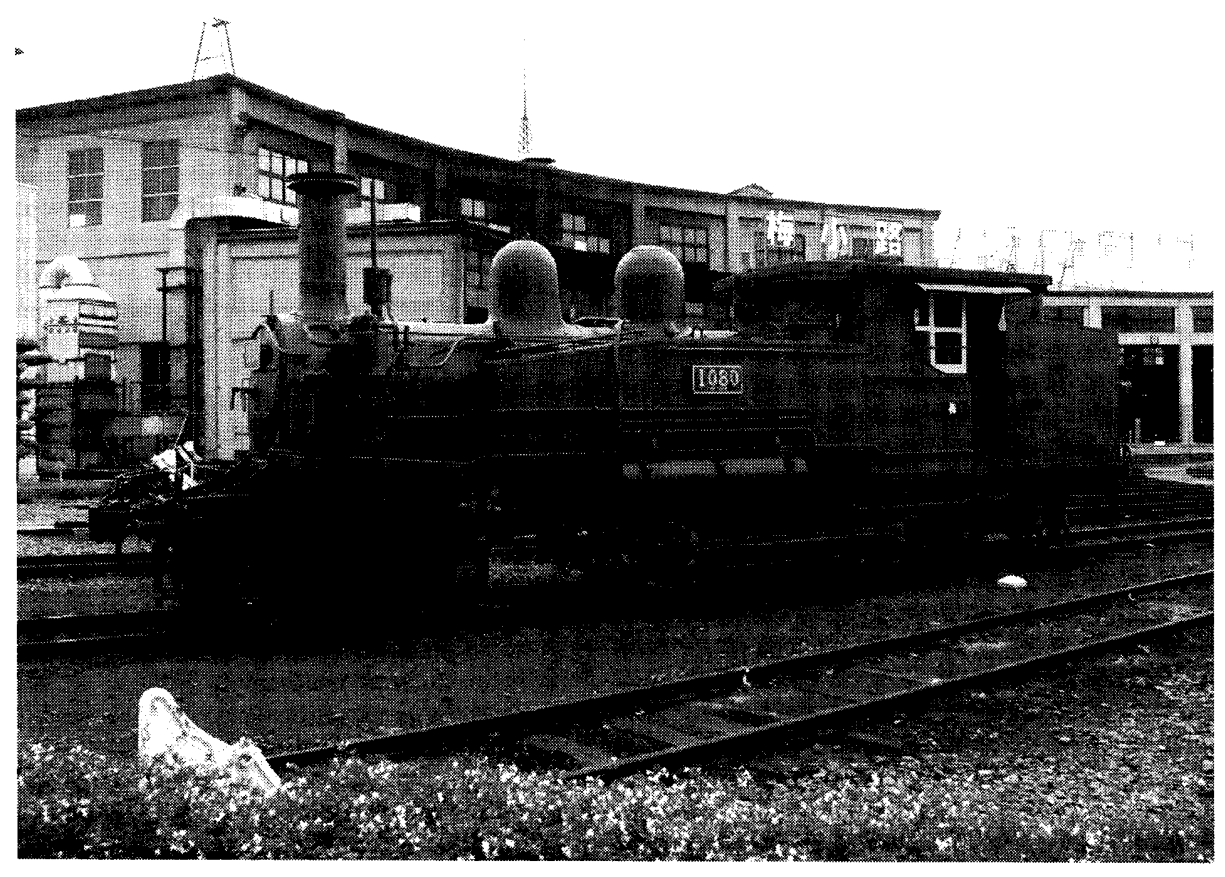

22. Front view of the No.1080 tank engine.

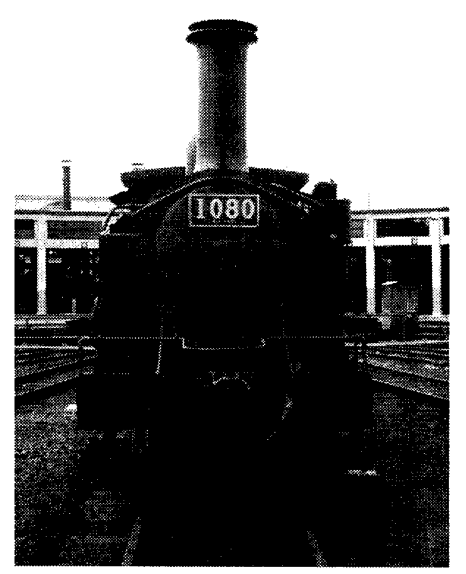




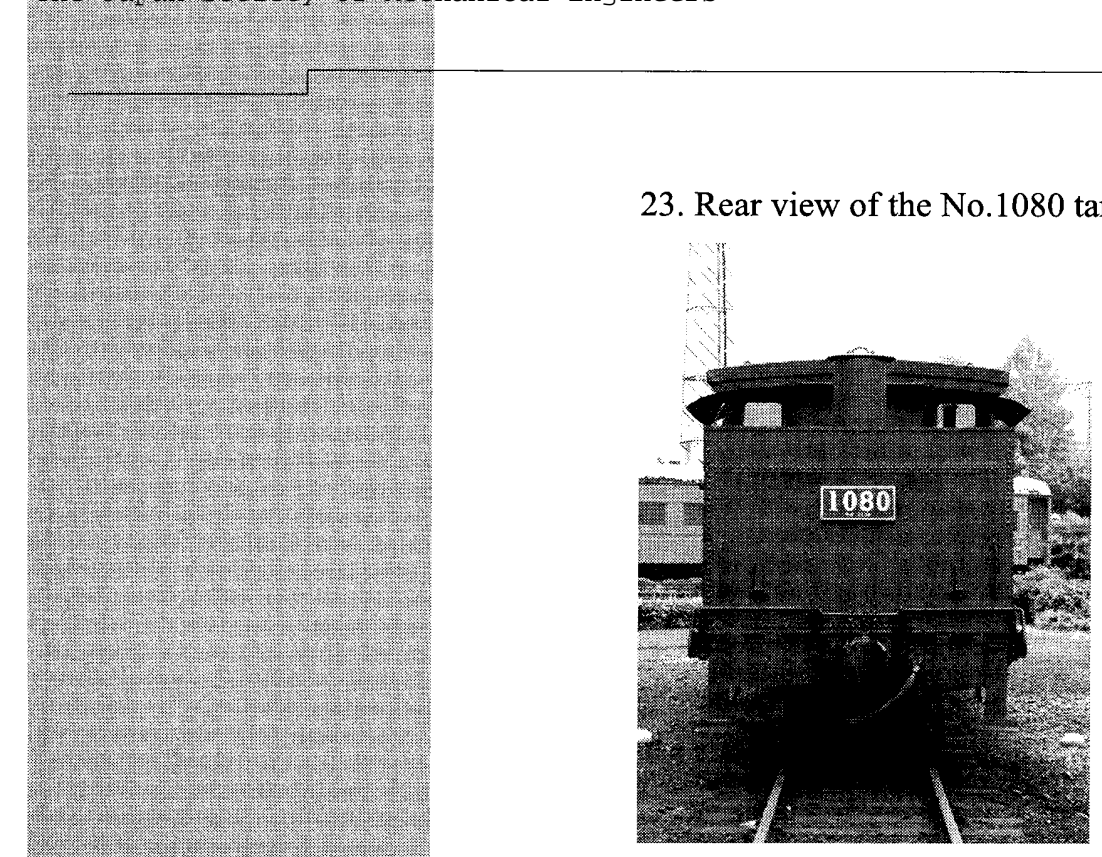

\section{Acknowledgement}

We are grateful to officers of Corporate Communication Department, Head Office of JR West and Umekoji Steam Locomotive Museum for their cooperation. 